UDC 576

LBC 22.311

\title{
LUBRICIN STRUCTURALAND FUNCTIONAL CHARACTERISTICS, ITS PARTICIPATION IN MAINTAINING ARTICULAR CARTILAGE TRIBOLOGICAL PARAMETERS
}

\author{
Tatyana S. Lyzo \\ Volgograd State University, Volgograd, Russian Federation \\ Pavel A. Krylov \\ Volgograd State University, Volgograd, Russian Federation
}

\begin{abstract}
Articular cartilage is constantly exposed to high loads. Wearing out of joints due to aging, as well as their poor functioning, is a common problem leading to a significant decline in the quality of human life. Lubricin is one of the main components of the biological lubrication system, it is a surface-active mucinous glycoprotein, which plays an important role in cartilage integrity. Its main function is to protect the cartilage surfaces from excessive friction - a necessary condition for maintaining the health of mammal joints. Moreover, lubricin has growth-regulating properties, it participates in the maturation of the subchondral bone and prevents cell adhesion. Although the molecule of lubricin was discovered almost half a century ago, there is still not much data available. The molecule has a great potential in medical applications. Studying lubricin can help solve problems caused by joint diseases, such as osteoarthritis. This review presents up-to-date information about structural and functional features of lubricin, its role in maintaining the integrity of articular cartilage, which can serve as a basis for the development of chondroprotectors or as a material to improve existing joint prostheses.
\end{abstract}

Key words: lubricin, PRG4, articular cartilage, osteoarthrosis, chondrocytes.

Citation. Lyzo T.S., Krylov P.A. Lubricin Structural and Functional Characteristics, Its Participation in Maintaining Articular Cartilage Tribological Parameters. Natural Systems and Resources, 2020, vol. 10, no. 1, pp. 22-28. (in Russian). DOI: https://doi.org/10.15688/nsr.jvolsu.2020.1.3

УДК 576

ББК 22.311

\section{СТРУКТУРНО-ФУНКЦИОНАЛЬНАЯ ХАРАКТЕРИСТИКА ЛУБРИЦИНА И УЧАСТИЕ В ПОДДЕРЖАНИИ ТРИБОЛОГИЧЕСКИХ ПАРАМЕТРОВ СУСТАВНОГО ХРЯЩА}

\author{
Татьяна Сергеевна Лызо
}

Волгоградский государственный университет, г. Волгоград, Российская Федерация

Павел Андреевич Крылов

Волгоградский государственный университет, г. Волгоград, Российская Федерация

Аннотация. Суставные хрящи постоянно подвергаются высоким нагрузкам. Изнашивание сустава в по-
илом возрасте, как и плохое функционирование в более молодом - очень распространенная проблема,
едущая к существенному уменьшению качества жизни человека. Лубрицин - один из основных компонентов
иологической смазки, это поверхностно-активный муцинозный гликопротеин, играющий важную роль в це-
остности хряща. Помимо основной функции - защиты хрящевых поверхностей от чрезмерного трения -
убрицин также обладает регулирующими рост свойствами, участвует в созревании субхондриальной кости и
репятствует адгезии клеток. Изучение лубрицина может способствовать решению проблем, вызванных бо- 
давно - почти полвека назад - о ней все еще известно очень мало. В данном обзоре максимально полно представлены структурные и функциональные особенности лубрицина, известные на сегодняшний день, подробно исследована его роль в поддержании целостности суставного хряща, что может послужить базисом для разработки хондропротекторов или как материал улучшения существующих суставных протезов.

Ключевые слова: лубрицин, PRG4, суставной хрящ, остеоартроз, хондроциты.

Цитирование. Лызо Т. С., Крылов П. А. Структурно-функциональная характеристика лубрицина и участие в поддержании трибологических параметров суставного хряща // Природные системы и ресурсы. 2020. - T. 10, № 1. - C. 22-28. - DOI: https://doi.org/10.15688/nsr.jvolsu.2020.1.3

Введение. Граничная смазка играет важную роль в суставных хрящах, подвергающихся высоким нагрузкам при низких скоростях скольжения [17]. В настоящее время считается, что три типа граничных смазок участвует в уменьшении трения в суставах: гиалуроновая кислота (ГК) [2], поверхностноактивные липиды [20], и лубрицин/PRG4, о котором и пойдет речь ниже [7; 11]. Лубрицин, впервые описанный Swann и соавторами [21], кодируется геном PRG4 (рис. 1) и представляет собой большой протеогликан. Этот белок содержит как хондроитинсульфат, так и кератансульфат-полимерные сульфатированные гликозаминогликаны. Лубрицин действует как граничная смазка на поверхности хряща и способствует упругому поглощению и рассеиванию энергии синовиальной жидкости. Мутации в этом гене приводят к синдрому камптодактилия-артропатии-тазика-вара-пе- рикардита. Альтернативный сплайсинг приводит к нескольким вариантам транскрипции [18]. Концентрация лубрицина в синовиальной жидкости составляет $\sim 250$ мкг/мл [12], а его молекулярная масса примерно равна 300 кДа [5].

Расположение в геноме человека. Лубрицин преимущественно синтезируется и экспрессируется хондроцитами поверхностной зонs хряща [8], но также может секретироваться синовиальными фибробластами [9]. Протеазакатепсин G может участвовать в деградации лубрицина в синовиальной жидкости, влияя на смазывание суставов [7]. Трансформирующий фактор роста $\beta$ (TGF- $\beta 1$ ) способен стимулировать секрецию лубрицина хондроцитами в поверхностной зоне суставного хряща, в то время как интерлейкин IL-1 $\alpha$ подавлял уровень экспрессии лубрицина и не влиял на инсулиноподобный фактор роста 1 (IGF-1). Аналогичный результат наблюдался в иссле-
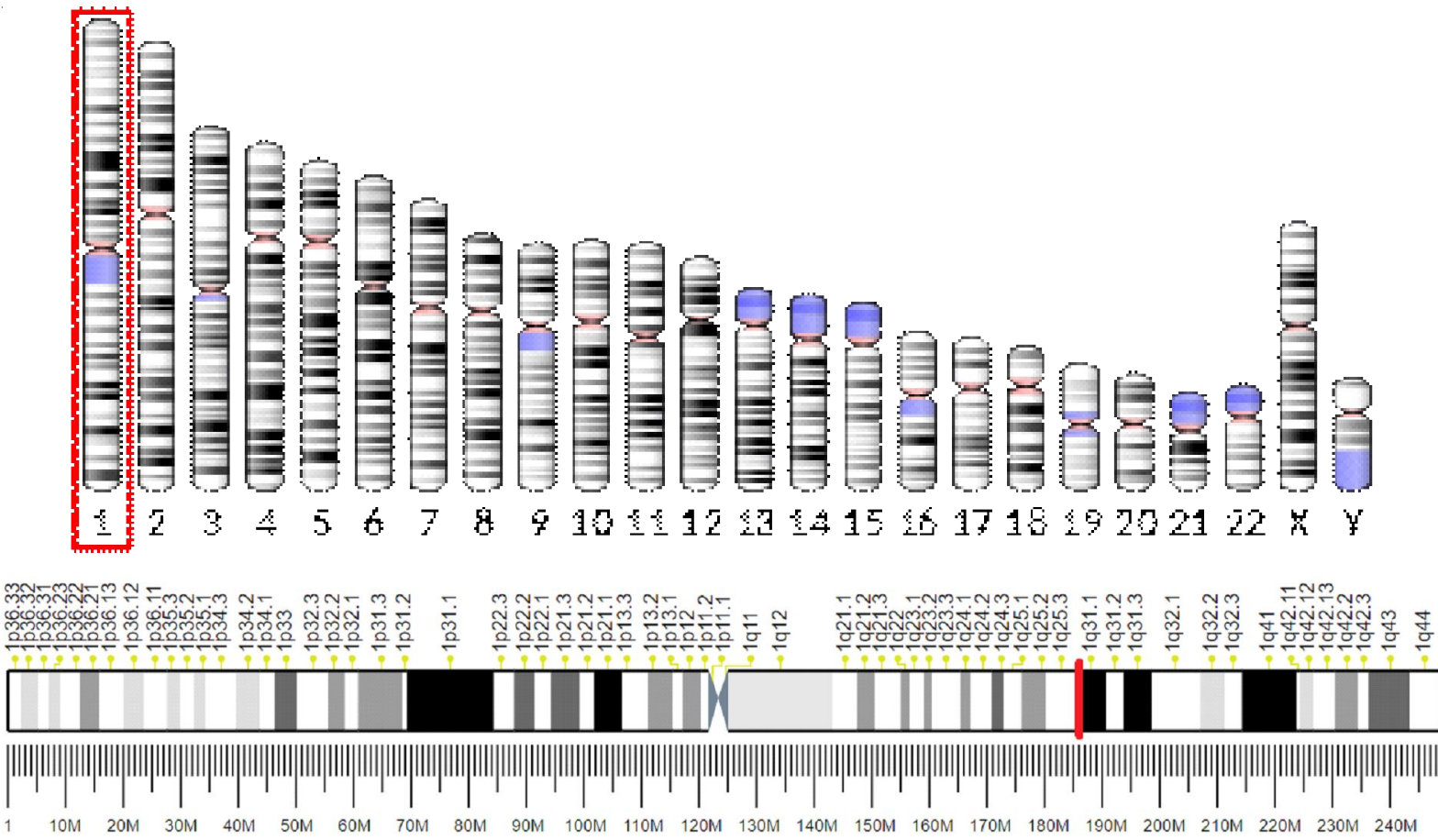

Рис. 1. Расположение PRG4 в геноме человека (отмечено красным) [5] 
довании Cheng и соавторов, в котором изучалась экспрессия PRG4, регулируемая либо IL$1 \alpha$, либо TGF- $\beta 1$. Хондроциты, выделенные из мыщелкового хряща 20-дневных крыс-самцов, показали антагонистический эффект в отношении уровня экспрессии мPHK PRG4: снижение IL- $1 \alpha$ и увеличение TGF- $\beta 1$. Доказано, что гликозаминогликаны на клеточной поверхности, такие как гепарансульфат (HS), гепарин и хондроитинсульфат (CS), оказывают влияние на ответ TGF- $\beta 1$, который активирует синтез лубрицина. Экзогенные HS и CS повышали уровень экспрессии лубрицина, в то время как гепарин демонстрировал противоположный ответ, затрудняя образование лубрицина. Также было обнаружено, что взаимодействие лубрицина с гиалуроновой кислотой оказывает существенное влияние на смазочную функцию, уменьшая энергию сдвига при совместном скольжении [15].

Структурно-функциональные свойства. Лубрицин представляет собой поверхностно-активный муцинозный гликопротеин, секретируемый в синовиальном суставе, который играет важную роль в целостности хряща. Лубрицин выглядит как бесструктурная, удлиненная и гибкая молекула диаметром в несколько нанометров [22]. При $\mathrm{pH}=7,2-7,6$ синовиальной жидкости молекула имеет небольшой суммарный положительный заряд, центральный домен заряжен отрицательно, конечные домены несут большую часть положительного заряда [13]. Лубрицин высоко консервативен у разных видов, в случае мышиной, крысиной, бычьей и человеческой смазок, демонстрирующих непостоянное количество остатков серина (>5\%) и треонина (>20\%) и реакционную способность к лектинам. Лубрицин имеет приблизительно равную массовую пропорцию белка и олигосахаридов [11].

Центральный муциновый домен фланкируется глобулярными N- и C-концами, которые могут быть полифункциональными [14]. Анализ аминокислотной последовательности лубрицина показывает, что он связан с витронектином. Оба белка содержат домен, подобный соматомедину В (SMB), и домен, подобный гемопексину, имеющий сходство последовательностей в этих областях более чем на $40 \%$.

Лубрицин не имеет специфической структуры и представляется в виде длинной и гиб- кой гликозилированной молекулы, однако он состоит из нескольких белковых доменов, которые выполняют отдельные биологические функции. Центром цепи является сильно гликозилированный длинный участок, который способствует тяжелой молекулярной массе лубрицина. Этот большой и муцинозный домен, сильно гликозилированная белковая часть с 76 аминокислотными повторами, экспрессируемыми с высокой частотой, в основном состоит из сахарных групп GalNAc, Gal и NeuAc, где остатки треонина О-связаны. При наличии большого количества отрицательно заряженных и сильно гидратированных сахарных групп этот центральный домен играет важную роль в смазывании благодаря сильному отталкиванию с помощью стерических и гидратирующих сил. Кроме того, существует много исследований, посвященных различным биологическим ролям белков, содержащих домен муцина, которые относятся к защите и адгезии эпителиальных поверхностей, регуляции дифференцировки клеток и контролю роста клеток.

Молекулярная структура лубрицина указывает на три разных домена: сильно гликозилированный - гидрофильная центральная часть, и концы - негликозилированные глобулярные домены (см. рис. 2). В то время как центральный домен в основном содержит отрицательно заряженные аминокислоты, концевые стороны содержат положительно заряженные и гидрофобные аминокислоты. Этот состав лубрицина демонстрирует высокое сходство с составом муциновых белков. Муцины, в частности, связываются с эпителиальными поверхностями и образуют гелеобразный защитный слой («слизь»), который создается молекулами, физически запутанными или ковалентно связанными путем образования дисульфидных связей между остатками цистеина [15].

Снижение трения между поверхностями, находящимися под давлением, и трением суставных поверхностей было изучено exvivo и invitro c небиологическими и хрящевыми поверхностями. В здоровых суставах молекулы лубрицина покрывают поверхность хряща, обеспечивая граничную смазку и предотвращая адгезию клеток и белка. Артропатия, возникающая у пациентов с травмой сустава, 


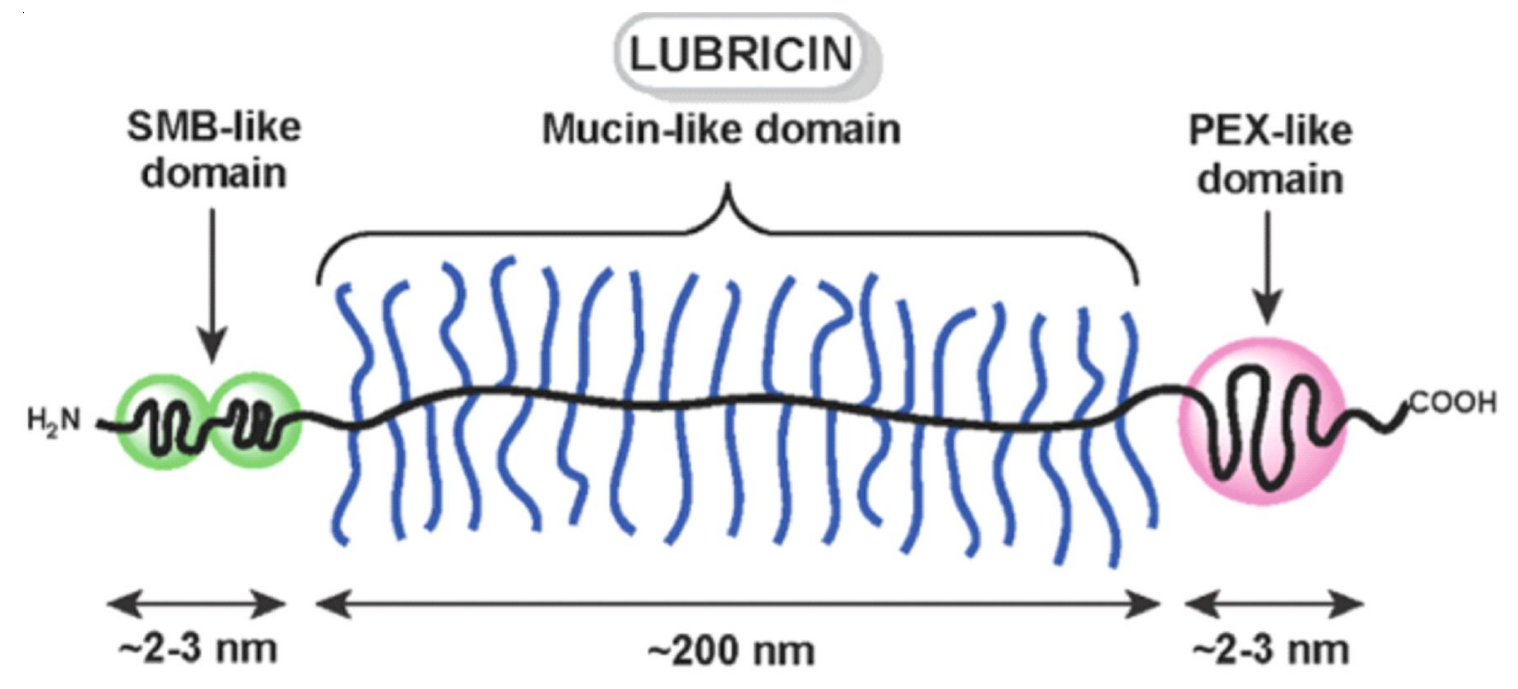

\section{$\begin{array}{lll}\text { ADHESIVE } & \text { REPULSIVE }\end{array}$}

Рис. 2. Схематическое представление лубрицина [3]

воспалительным артритом или генетически обусловленным дефицитом лубрицина, выражается вего недостаточном количестве для предотвращения повреждения суставного хряща [14]. Кроме того, лубрицин предотвращает осаждение белка на поверхность хряща из синовиальной жидкости, контролирует ее увеличение в зависимости от адгезии и ингибирует прилипание синовиальных клеток к поверхности хряща. Было предположено, что лубрицин, также известный как белок поверхностной зоны (SZP), обладает потенциальными биологическими функциями, такими как пролиферация клеток, цитопротекция и самоагрегация и связывание матрикса. В отсутствие смазки синовиальные суставы могут вызвать дисфункцию, которая приводит к патогенезу дегенерации хряща. С другой стороны, помимо всех вышеперечисленных полезных свойств смазки для суставного хряща, в исследовании утверждается, что смазка покрывает поверхности поврежденного хряща и препятствует интегративному восстановлению [15].

Граничная смазка преобладает в периоды высокой нагрузки и низкой скорости, когда слой смазочной пленки тоньше, чем шероховатость поверхности. В здоровых суставных суставах слой молекул лубрицина покрывает поверхность хряща и действует как антиадгезивная граничная смазка, предотвращая повреждение хряща, когда неровности повер- хности движутся друг против друга. В опоpax, которые не были смазаны лубрицином, клетки, расположенные чуть ниже сплющенных клеток на поверхности хряща, оказались наиболее подверженными риску апоптоза [24].

Помимо основной функции смазки, лубрицин также обладает регулирующими рост свойствами [16], предотвращает адгезию клеток, обеспечивает хондропротекцию [4] и играет роль в созревании субхондральной кости [1]. Кроме того, лубрицин защищает поверхность хряща от чрезмерной адсорбции белков и клеток, которая является причиной преждевременной суставной недостаточности при генетических заболеваниях [23].

Лубрицин и ГК, являющиеся частью синовиальной жидкости, это основные факторы, способствующие эффективной смазке суставов и защите от износа. Исследования на животных моделях и искусственных системах позволяют предположить, что молекулы лубрицина и ГК могут работать в тандеме, создавая синергетический эффект. Однако последние наблюдения показывают, что лубрицин обладает более значительным потенциалом для защиты суставов, чем ГК [10]. Смазывающие способности лубрицина возникают из двух ключевых структурных особенностей: (1) плотный муциноподобный домен, состоящий из гидрофильных олигосахаридов и (2) концы, которые прикрепляет молекулу к сочленяющимся поверхностям. Когда они свя- 
заны, молекула притягивает и удерживает воду у поверхности, уменьшая трение и облегчая скольжение [19].

Заключение. Долговременная целостность сустава зависит от питания его хрящевого компонента и защиты поверхности хряща от износа, вызванного трением. Лубрицин поверхностно-активный муцинозный гликопротеин, секретируемый в синовиальном суставе, играет важную роль в целостности хряща. Помимо основной функции - смазки для суставных границ - лубрицин также может регулировать скорость нарастания хрящевого компонента, предотвращает слипание клеток в синовиальной жидкости, может замедлять развитие суставных болезней и играет роль в созревании субхондральной кости. Дальнейшее изучение структурно-функциональных свойств лубрицина позволит решить проблемы развития остеоартроза.

\section{СПИСОК ЛИТЕРАТУРЫ}

1. Abubacker, S. Absence of Proteoglycan 4 (Prg4) Leads to Increased Subchondral Bone Porosity Which Can Be Mitigated Through Intra-Articular Injection of PRG4 / S. Abubacker, P. Premnath, A. Shonak // Journal of Orthopaedic Research. -2019. Vol. 37, № 10. - P. 2077-2088. - DOI: https://doi.org/ 10.1002/jor.24378.

2. Bell, C. Influence of Hyaluronic Acid on the Time-Dependent Friction Response of Articular Cartilage Under Different Conditions / C. J. Bell, E. Ingham, J. Fisher // Proceedings of the Institution of Mechanical Engineers, Part H. - 2006. - Vol. 220, № 1.P.23-31.-DOI: https://doi.org/10.1243/095441105X69060.

3. Bioinspired Bottlebrush Polymer Exhibits Low Friction and Amontons-Like Behavior / X. Banquy [et al.] // Journal of the American Chemical Society. 2014. - Vol. 136, № 17. - P. 6199-6202. - DOI: https:// doi.org/10.1021/ja501770y.

4. Cartilage Shear Dynamics During TibioFemoral Articulation: Effect of Acute Joint Injury and Tribosupplementation on Synovial Fluid Lubrication / B. Wong [et al.] // Osteoarthritis Cartilage. - 2010. - Vol. 18, № 3. - P. 464-471. - DOI: http://dx.doi.org/10.1016/j.joca.2009.11.008.

5. Cathepsin g Degrades Synovial Fluid Lubricin: Relevance for Osteoarthritis Pathogenesis / S. Huang [et al.] // BioRxiv. - 2019. - P. 792184. - DOI: https://doi.org/10.1101/792184.

6. Chromosome 1. - Электрон. текстовые дан. Режим доступа: http://asia.ensembl.org/Homo_
sapiens/Location/Chromosome?r=1 (дата обращения: 13.04.2020). - Загл. с экрана.

7. Conformational Mechanics, Adsorption, and Normal Force Interactions of Lubricin and Hyaluronic Acid on Model Surfaces / D. P. Chang [et al.] // Langmuir. - 2008. - Vol. 24, № 4. - P. 1183-1193. DOI: https://doi.org/10.1021/la702366t.

8. Flannery, C. Articular Cartilage Superficial Zone Protein (SZP) is Homologous to Megakaryocyte Stimulating Factor Precursor and is a Multifunctional Proteoglycan with Potential Growth-Promoting, Cytoprotective, and Lubricating Properties in Cartilage Metabolism / C. Flannery, C. Hughes, B. Schumacher // Biochemical and Biophysical Research Communications. - 1999. - Vol. 254, № 3. - P. 535541. -DOI: https://doi.org/10.1006/bbrc.1998.0104.

9. Homology of Lubricin and Superficial Zone Protein (SZP): Products of Megakaryocyte Stimulating Factor (MSF) Gene Expression by Human Synovial Fibroblasts and Articular Chondrocytes Localized to Chromosome 1q25 / G. Jay, U. Tantravahi, D. Britt [et al.] // Journal of Orthopaedic Research. -2001. -P. 677-687. DOI: https://doi.org/10.1016/S0736-0266(00)00040-1.

10. Ilker, S. Advances in Tribology of Lubricin and Lubricin-Like Synthetic Polymer Nanostructures / S. Ilker // Smart Materials. - 2018. - Vol. 6, № 2. P. 30. - DOI: https://doi.org/10.3390/lubricants6020030.

11. Jay, G. D. Boundary Lubrication by Lubricin is Mediated by O-Linked в (1-3)Gal-GalNAc Oligosaccharides / G. D. Jay, D. A. Harris, C. J. Cha // Glycoconjugate Journal. - 2001. - Vol. 18. - P. 807815. - DOI: https://doi.org/10.1023/A:1021159619373.

12. Jay, G. D. Lubricin and Surfacing of Articular Joints / G. D. Jay // Current Opinion in Orthopaedics. 2004. - Vol. 15, № 5. - P. 355-359.

13. Jay, G. Joint Lubrication: a Physico-Chemical Study of a Purified Lubricating Factor from Bovine Synovial Fluid / PhD Thesis. - N.Y. : State University of New York, Stony Brook, 1990.

14. Jay, G. The Biology of Lubricin: Near Frictionless Joint Motion / G. Jay, K. Waller // Matrix Biology. - 2014. - Vol. 39. - P. 17-24. - DOI: https:// doi.org/10.1016/j.matbio.2014.08.008.

15. Lee, Y. Regulation of Lubricin for Functional Cartilage Tissue Regeneration: a Review / Y. Lee, J. Choi, N. Hwang // Biomaterials Research. - 2018. Vol. 22, № 9. - DOI: http://dx.doi.org/10.1186/s40824018-0118-x.

16. Marcelino, J. CACP, Encoding a Secreted Proteoglycan, is Mutated in Camptodactylyarthropathy-Coxa Vara-Pericarditis Syndrome / J. Marcelino, J. Carpten, W. Suwairi // Nature Genetics. - 1999. - Vol. 23, № 3. - P. 319-322. - DOI: https://doi.org/10.1038/15496.

17. Mow, V. Cartilage and Diarthrodial Joints as Paradigms for Hierarchical Materials and Structures 
/ V. Mow, A. Ratcliffe, A. Poole// Biomaterials. - 1992. Vol. 13, № 2. - P. 67-97. - DOI: https://doi.org/10.1016/ 0142-9612(92)90001-5.

18. PRG4 proteoglycan 4 [Homo sapiens (human)].Электрон. текстовые дан. - Режим доступа: https:// www.ncbi.nlm.nih.gov/gene? Db=gene\& Cmd=ShowDetail View\&TermToSearch=10216\#gene-expression (дата обращения: 13.04.2020). - Загл. с экрана.

19. Samaroo, K. Binding and Lubrication of Biomimetic Boundary Lubricants on Articular Cartilage / K. Samaroo, M. Tan, D. Putnam, L. Bonassar// Journal of Orthopaedic Research. - 2017. - Vol. 35, № 3. P. 548-557. - DOI: http://dx.doi.org/10.1002/jor.23370.

20. Schwarz, I. Surface-Active Phospholipid as the Lubricating Component of Lubricin / I. M. Schwarz, B. A. Hills // British Journal of Rheumatology. - 1998. Vol. 31, № 1. - P. 21-26. - DOI: https://doi.org/10.1093/ rheumatology/37.1.21.

21. Swann, D. A. The Molecular Basis of Articular Lubrication, Purification and Properties of a Lubricating Fraction from Bovine Synovial Fluid / D. A. Swann, E. L. Radin // Journal of Biological Chemistry. - 1972. - Vol. 247, № 24. - P. 8069-8073.

22. Swann, D. The Molecular Structure of Lubricating Glycoprotein-I, the Boundary Lubricant for Articular Cartilage / D. Swann, H. Slayter, F. Silver // Journal of Biological Chemistry. - 1981. - Vol. 256. P. 5921-5925.

23. The Secreted Glycoprotein Lubricin Protects Cartilage Surfaces and Inhibits Synovial Cell Overgrowth / D. Rhee [et al.] // Journal of Clinical Investigation. - 2005. - Vol. 115, № 3. - P. 622-631.DOI: https://doi.org/10.1172/JCI22263.

24. Waller, K. Role of Lubricin and Boundary Lubrication in the Prevention of Chondrocyte Apoptosis / K. Waller, L. Zhang, K. Elsaid // Proceedings of the National Academy of Sciences. 2013. - Vol. 110, № 15. - P. 5852-5857. - DOI: https:// doi.org/10.1073/pnas. 1219289110.

\section{REFERENCES}

1. Abubacker S., Premnath P., Shonak A. et al. Absence of Proteoglycan 4 (Prg4) Leads to Increased Subchondral Bone Porosity Which Can Be Mitigated Through Intra-Articular Injection of PRG4. Journal of Orthopaedic Research, 2019, vol. 37, no. 10, pp. 2077 2088. DOI: https://doi.org/10.1002/jor.24378.

2. Bell C.J., Ingham E., Fisher J. Influence of Hyaluronic Acid on the Time-Dependent Friction Response of Articular Cartilage Under Different Conditions. Proceedings of the Institution of Mechanical Engineers, Part H: Journal of Engineering in Medicine, 2006, vol. 220, no. 1, pp. 2331. DOI: https://doi.org/10.1243/095441105X69060.
3. Banquy X., Burdycska J., Lee D.W. et al. Bioinspired Bottle-Brush Polymer Exhibits Low Friction and Amontons-like Behavior. Journal of the American Chemical Society, 2014, vol. 136, no. 17, pp. 6199-6202. DOI: https://doi.org/10.1021/ja501770y.

4. Wong, B. L., Kim, S. H. C., Antonacci, J. M. et al. Cartilage Shear Dynamics During Tibio-Femoral Articulation: Effect of Acute Joint Injury and Tribosupplementation on Synovial Fluid Lubrication. Osteoarthritis and Cartilage, 2010, vol. 18, no. 3, pp. 464471. DOI: http://dx.doi.org/10.1016/j.joca.2009.11.008.

5. Huang S., Thomsson K.A., Jin C. et al. Cathepsin g Degrades Synovial Fluid Lubricin: Relevance for Osteoarthritis Pathogenesis. BioRxiv, 2019, pp. 792184. DOI: https://doi.org/10.1101/792184.

6. Chromosome 1. URL: http://www.ensembl. org/Homo_sapiens/Location/Chromosome? $\mathrm{r}=1$ (accessed 13 April 2020).

7. Chang D.P., Abu-Lail N.I., Guilak et al. Conformational Mechanics, Adsorption, and Normal Force Interactions of Lubricin and Hyaluronic Acid on Model Surfaces. Langmuir, 2008, vol. 24, no. 4, pp. 1183-1193. DOI: https://doi.org/10.1021/la702366t.

8. Flannery C.R., Hughes C.E., Schumacher B.L. et al. Articular Cartilage Superficial Zone Protein (SZP) Is Homologous to Megakaryocyte Stimulating Factor Precursor and Is a Multifunctional Proteoglycan With Potential Growth-Promoting, Cytoprotective, and Lubricating Properties in Cartilage Metabolism. Biochemical and Biophysical Research Communications, 1999, vol. 254, no. 3, pp. 535-541. DOI: https://doi.org/10.1006/bbrc.1998.0104.

9. Jay G.D., Tantravahi U., Britt D.E. et al. Homology of Lubricin and Superficial Zone Protein (SZP): Products of Megakaryocyte Stimulating Factor (MSF) Gene Expression by Human Synovial Fibroblasts and Articular Chondrocytes Localized to Chromosome 1q25. Journal of Orthopaedic Research, 2001, vol. 19, no. 4, pp. 677-687. DOI: https://doi.org/10.1016/S07360266(00)00040-1.

10. Ilker S. Advances in Tribology of Lubricin and Lubricin-like Synthetic Polymer Nanostructures. Lubricants, 2018, vol. 6, no. 2, p. 30. DOI: https:// doi.org/10.3390/lubricants6020030.

11. Jay G.D., Harris D.A., Cha C.J. Boundary Lubrication by Lubricin Is Mediated by O-linked в(1-3)Gal-GalNAc Oligosaccharides. Glycoconjugate Journal, 2001, vol. 18, no. 10, pp. 807-815. DOI: https:// doi.org/10.1023/A:1021159619373.

12. Jay G.D. Lubricin and Surfacing of Articular Joints. Current Opinion in Orthopedics, 2004, vol. 15, no. 5, pp. 355-359.

13. Jay G.D. Joint Lubrication: A PhysicoChemical Study of a Purified Lubricating Factor From Bovine Synovial Fluid. PhD Thesis. New York, State University of New York, Stony Brook, 1990. 
14. Jay G.D., Waller K.A. The Biology of Lubricin: Near Frictionless Joint Motion. Matrix Biology, 2014, vol. 39, pp. 17-24. DOI: https://doi.org/ 10.1016/j.matbio.2014.08.008.

15. Lee Y., Choi J., Hwang N.S. Regulation of Lubricin for Functional Cartilage Tissue Regeneration: A Review. Biomaterials Research, 2018, vol. 22, no. 9. DOI: http://dx.doi.org/10.1186/s40824-018-0118-x.

16. Marcelino, J., Carpten, J. D., Suwairi, W. M. et al. CACP, Encoding a Secreted Proteoglycan, Ismutated in Camptodactyly-Arthropathy-Coxa Vara-Pericarditis Syndrome. Nature Genetics, 1999, vol. 23, no. 3, pp. 319-322. DOI: https://doi.org/ $10.1038 / 15496$.

17. Mow V.C., Ratcliffe A., Robin Poole A. Cartilage and Diarthrodial Joints as Paradigms for Hierarchical Materials and Structures. Biomaterials, 1992, vol. 13, no. 2, pp. 67-97. DOI: https://doi.org/ 10.1016/0142-9612(92)90001-5.

18. PRG4 Proteoglycan 4 [Homo Sapiens (Human)]. URL: https://www.ncbi.nlm.nih.gov/gene? $\mathrm{Db}=$ gene\&Cmd $=$ ShowDetailView\&TermToSearch $=10216 \#$ gene-expression (accessed 17 April 2020).

19. Samaroo K.J., Tan M., Putnam D. et al. Binding and Lubrication of Biomimetic Boundary Lubricants on Articular Cartilage. Journal of Orthopaedic
Research, 2016, vol. 35, no. 3, pp. 548-557. DOI: http:// dx.doi.org/10.1002/jor.23370.

20. Schwarz I.M., Hills B.A. Surface-Active Phospholipid as the Lubricating Component of Lubricin. British Journal of Rheumatology, 1998, vol. 31, no. 1, pp. 21-26. DOI: https://doi.org/10.1093/ rheumatology/37.1.21.

21. Swann D.A., Radin E.L. The Molecular Basis of Articular Lubrication, Purification and Properties of a Lubricating Fraction From Bovine Synovial Fluid. J Biol Chem, 1972, vol. 247, no. 24, pp. 8069-8073.

22. Swann D.A., Slayter H.S., Silver F.H. The Molecular Structure of Lubricating Glycoprotein-I, the Boundary Lubricant for Articular Cartilage. Journal of Biol Chem, 1981, vol. 256, no. 11, pp. 5921-5925.

23. Rhee D.K., Marcelino J., Baker M. et al. The Secreted Glycoprotein Lubricin Protects Cartilage Surfaces and Inhibits Synovial Cell Overgrowth. Journal of Clinical Investigation, 2005, vol. 115, no. 3, pp. 622-631. DOI: https://doi.org/10.1172/JCI22263.

24. Waller K.A., Zhang L.X., Elsaid K.A. et al. Role of Lubricin and Boundary Lubrication in the Prevention of Chondrocyte Apoptosis. Proceedings of the National Academy of Sciences, 2013, vol. 110, no. 15 , pp. 5852-5857. DOI: https://doi.org/10.1073/ pnas. 1219289110.

\section{Information About the Authors}

Tatyana S. Lyzo, Student, Department of Bioengineering and Bioinformatics, Volgograd State University, Prosp. Universitetsky, 100, 400062 Volgograd, Russian Federation, bib-171_799672@volsu.ru.

Pavel A. Krylov, Candidate of Sciences (Biology), Associate Professor, Department of Bioengineering and Bioinformatics, Volgograd State University, Prosp. Universitetsky, 100, 400062 Volgograd, Russian Federation, krylov.pavel@volsu.ru.

\section{Информация об авторах}

Татьяна Сергеевна Лызо, студент кафедры биоинженерии и биоинформатики, Волгоградский государственный университет, просп. Университетский, 100, 400062 г. Волгоград, Российская Федерация, bib-171_799672@volsu.ru.

Павел Андреевич Крылов, кандидат биологических наук, доцент кафедры биоинженерии и биоинформатики, Волгоградский государственный университет, просп. Университетский, 100, 400062 г. Волгоград, Российская Федерация, krylov.pavel@volsu.ru. 